\title{
Aerobic Oxidation of Alcohols and the Synthesis of Benzoxazoles Catalyzed by a Cuprocupric Coordination Polymer ( $\left.\mathrm{Cu}^{+}-\mathrm{CP}\right)$ Assisted by TEMPO
}

\author{
Xun Feng, ${ }^{\dagger}$ Chen Xu, ${ }^{* \dagger}$ Zhi-Qiang Wang, ${ }^{\dagger}$ Si-Fu Tang, ${ }^{\dagger}$ Wei-Jun Fu, ${ }^{\dagger}$ Bao-Ming Ji, ${ }^{\dagger}$ and Li-Ya Wang ${ }^{*},{ }^{\dagger} \S$ \\ ${ }^{\dagger}$ College of Chemistry and Chemical Engineering, Luoyang Normal University, Luoyang 471022, China \\ ${ }^{\ddagger}$ Qingdao Institute of Bioenergy and Bioprocess Technology, Chinese Academy of Sciences, Qingdao 266101, China \\ ${ }^{\S}$ College of Chemistry and Pharmacy Engineering, Nanyang Normal University, Nanyang 473601, China
}

Supporting Information

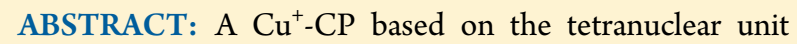
$\left\{\left[(\mathrm{HSQPA})_{2} \mathrm{Cu}_{4}(\text { bipy })_{4}\right] \cdot 2 \mathrm{H}_{2} \mathrm{O}\right\}_{n} \cdot 2 n \mathrm{H}_{2} \mathrm{O}$ has been constructed through $\mathrm{Cu}^{2+}$ salt, 2-(sulfonylquinlium-8-yloxy)phthalic acid ( $\left.\mathrm{H}_{3} \mathrm{SQPA}\right)$, and 4,4'-bipyridine (bipy). This $\mathrm{Cu}^{+}-\mathrm{CP}$ combined with 2,2,6,6-tetramethylpiperidine-1oxyl as the cocatalyst is an effective catalyst for aerobic oxidation of alcohols and the synthesis of benzoxazoles and can be recycled at least four times without losing its catalytic activity.

$\mathrm{T}$ he oxidation of alcohols to the corresponding carbonyl compounds is one of the most important reactions in organic synthesis, and extensive efforts have been focused on the development of metal-catalyzed aerobic oxidation methods. ${ }^{1}$ It traditionally requires numerous stoichiometric oxidants and expensive metal catalysts such as palladium and ruthenium. ${ }^{2}$ Copper compounds are well established among the known alcohol oxidation catalysts; ${ }^{3}$ those employing 2,2,6,6-tetramethylpiperidine-1-oxyl (TEMPO) as a redox-active cocatalyst were particularly effective for the aerobic oxidation of alcohols and exhibited broad utilities in both academe and industry. ${ }^{4}$ In contrast to the great development of homogeneous copperbased catalysts, only two supported copper catalysts have been reported, ${ }^{5}$ and heterogeneous copper catalyst systems are still largely unexplored.

On the other hand, coordination polymers and metal-organic frameworks (MOFs) have emerged as a new class of attractive functional materials with considerable promise in catalysis. ${ }^{6}$ These heterogeneous catalysts can be readily recovered and reused while possessing spatially separated single catalytic active sites in their frameworks, which is highly desirable for cost and sustainability considerations. Some monounclear copper complexes with $\mathrm{N}, \mathrm{N}$ and $\mathrm{N}, \mathrm{O}$ ligands in conjunction with TEMPO were found to be efficient catalysts for the aerobic oxidation of alcohols. ${ }^{7}$ However, only four examples of $\mathrm{Cu}^{2+}-\mathrm{MOF}$ derived from tricarboxylic ligands ${ }^{8}$ and 4,7-bis(4-pyridyl)-1,1,3,3-tetramethylisoindolin-2-yloxy ${ }^{9}$ have been reported to be effective catalysts for the aerobic oxidation of alcohols, and these catalyst systems require an oxygen atmosphere or tert-butyl nitrite. To our best of knowledge, there are presently no reports concerning a $\mathrm{Cu}^{+}-\mathrm{MOF} / \mathrm{CP}$ catalyst system for the aerobic oxidation of alcohols. Our recent works on $\mathrm{Pd} / \mathrm{Cu}$-cocatalyzed aerobic alcohol oxidation and the synthesis of $\mathrm{CPs}^{10}$ prompted us to explore the possibility of $\mathrm{Cu}^{+}-\mathrm{CP}$ as a reusable catalyst in the aerobic oxidation of alcohols. Herein, we report the synthesis and structural characterization of six-coordinated $\mathrm{Cu}^{\mathrm{II}}$ complex $\mathbf{1}$ and four-coordinated $\mathrm{Cu}^{\mathrm{I}}$ complex $\mathbf{2}$ and present an effective procedure for the aerobic oxidation of primary and secondary alcohols to the aldehydes, ketones, and benzoxazoles using a reusable heterogeneous $\mathrm{Cu}^{+}-\mathrm{CP}$ 2/TEMPO catalytic system under an air atmosphere.

The $\mathrm{Cu}^{2+}-\mathrm{CP} 1,\left\{\left[\mathrm{Cu}_{2}(\mathrm{SQPA})_{2}\right] \cdot 2 \mathrm{H}_{2} \mathrm{O}\right\}_{n} \cdot 2 n \mathrm{H}_{2} \mathrm{O}$, was obtained by mixing the ligand 2-(sulfonylquinlium-8-yloxy)phthalic acid ( $\left.\mathrm{H}_{3} \mathrm{SQPA}\right)$ and copper(II) acetate under solvothermal conditions. The asymmetric unit of $\mathbf{1}$ is simply composed of one $\mathrm{Cu}^{\mathrm{II}}$ center supported by HSQPA ligands and two coordination molecules, as well as one lattice water molecule, as shown in Figure S2a in the Supporting Information (SI). The two head-to-tail arrangements of the HSQPA ligands adopt the same chelating modes, which link the $\mathrm{Cu}^{\mathrm{II}}$ centers to generate a dimer unit with a metal-metal distance of $8.49 \AA$. These units are further extended by an $\mathrm{O}$ atom of the sulfonic group to form a railway-like double-chain aggregate (Figure 1).

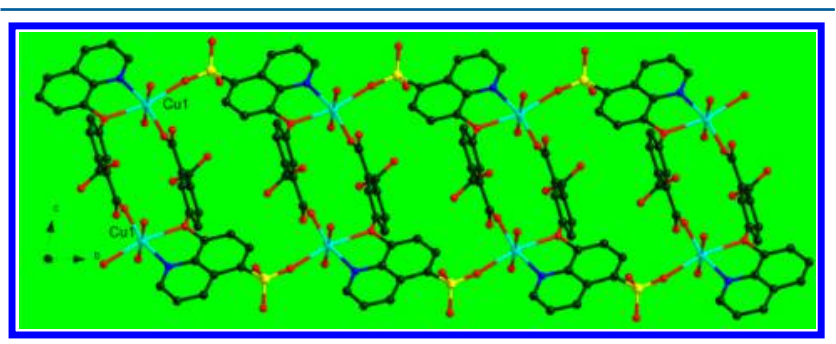

Figure 1. Ball-and-stick view of the $1 \mathrm{D}$ packing array in $\mathbf{1}$.

The $\mathrm{Cu}^{+}-\mathrm{CP} 2$ was prepared in high yield by mixing ligands $\mathrm{H}_{3} \mathrm{SQPA}$ and bipy and copper(II) acetate under solvothermal conditions. Interestingly, the $\mathrm{Cu}^{\mathrm{II}}$ ions were reduced to $\mathrm{Cu}^{\mathrm{I}}$ ions by in situ reaction owing to the reducibility of the bipy moiety at high temperature. ${ }^{11}$ Single-crystal X-ray diffraction (XRD) analysis reveals that $\mathbf{2}$ crystallizes in a triclinic system. The asymmetric unit of $\mathbf{2}$ is composed of two types of $\mathrm{Cu}^{\mathrm{I}}$ ions, two bipy molecules, two deprotonated $\left(-\mathrm{SO}_{3} \mathrm{H}\right.$ and $\left.-\mathrm{COOH}\right)$

Received: December 4, 2014

Published: February 17, 2015 
HSQPA ligands, and two coordinated and one lattice water molecules (Figure S2b in the SI). Both $\mathrm{Cu}^{\mathrm{I}}$ ions exhibit a fourcoordinated tetrahedral environment with a $\mathrm{N}_{2} \mathrm{O}_{2}$ donor set provided by HSQPA, bipy linker moieties, and the coordinated water. Four adjacent $\mathrm{Cu}^{\mathrm{I}}$ ions form a tetranuclear cluster through a $\mathrm{O} / \mathrm{N}$ linker. These units are further interconnected by bipy ligands, resulting in a $2 \mathrm{D}$ layer, as shown in Figure 2a. The $\mathrm{Cu} 2$

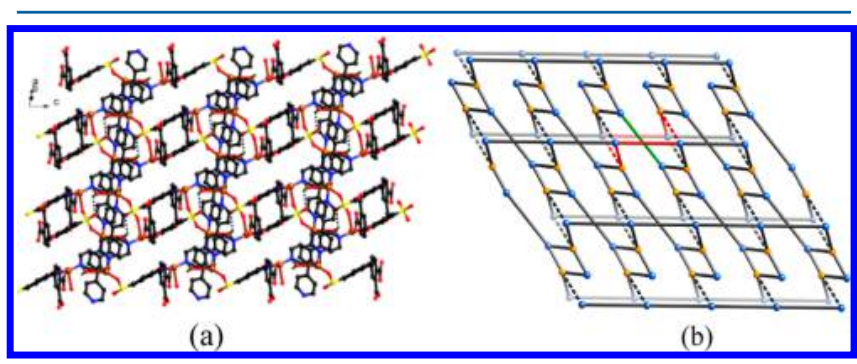

Figure 2. (a) 2D packing array in 2. (b) Schematic view of the $(3,4)$ connected $(4.6 .8)\left(4.6^{4} .8\right)\left(4^{2} .6^{2} .8^{2}\right)$ topology. A 6-membered short circuit is highlighted in red, and the rod passing through it is highlighted in green (orange nodes are for $\mathrm{Cu}^{\mathrm{I}}$ centers and blue nodes for $\mathrm{H}_{3} \mathrm{SQPA}$ ligands).

ion is coordinated to one HSQPA and two bipy ligands through $\mathrm{Cu}-\mathrm{O} / \mathrm{N}$ bonds, while the $\mathrm{Cu} 1$ and HSQPA ligand link four moieties. $\mathrm{Cu} 1, \mathrm{Cu} 2$, and HSQPA ligand can be regarded as 3 and 4-connected nodes, topologically, and the layer can be reduced to a $(3,4)$-connected network with a Schläfli symbol of (4.6.8)$\left(4.6^{4} .8\right)\left(4^{2} .6^{2} .8^{2}\right)$ (Figure $\left.2 b\right)$.

Thermogravimetric/differential thermal analysis (Figure S3 in the SI) indicates that a dehydrate of $\mathbf{2}$ can be kept intact beyond $300{ }^{\circ} \mathrm{C}$, followed by expulsion of organic components. In order to confirm the oxidation states of the $\mathrm{Cu}$ ion, magnetic susceptibility and X-ray photoelectron spectroscopy measurements were performed. The former indicates that $\mathbf{2}$ is just a diamagnetic material (Figure S4 in the SI). The spin-orbit components $\left(2 \mathrm{p}_{3 / 2}\right.$ and $\left.2 \mathrm{p}_{1 / 2}\right)$ of the $\mathrm{Cu} 2 \mathrm{p}$ peak were well deconvoluted by two curves at approximately 932.2 and $952.1 \mathrm{eV}$ with a spin-orbit separation of $19.9 \mathrm{eV}$ (Figure S5 in the SI), confirming the presence of a monovalent oxidation state of $\mathrm{Cu}^{\mathrm{I}}$ in 2 . $^{12}$ The pure 2 was confirmed by powder XRD measurement, in which diffraction peaks of experimental data are in agreement with the simulated data from single-crystal X-ray crystallography (Figure S6 in the SI).

Initially, the oxidation of benzylic alcohol was chosen as a model reaction to optimize the reaction conditions under an air atmosphere (Table S3 in the SI). A blank reaction was carried out with $\mathrm{KOH}$ as the base in $\mathrm{CH}_{3} \mathrm{CN}$; negligible product benzaldehyde was attained. An additional blank experiment was performed under similar conditions using $2 \mathrm{~mol} \% \mathrm{Cu}^{+}-\mathrm{CP}$; the isolated yield of benzaldehyde was only $28 \%$ (entry 1 ). However, the yield was greatly improved by the addition of TEMPO (70\%, entry 2). The $\mathrm{Cu}^{2+}-\mathrm{CP} 1$ generated the product only in $16 \%$ yield under the same conditions (entry 3 ). After a variety of solvents were screened, $\mathrm{CH}_{3} \mathrm{CN}$ was found to be the most effective solvent and toluene showed a comparable result (entry 6). Then, in a quick survey of the bases, $\mathrm{CsOH}$ was found to give the best result (entry 12) and $\mathrm{Cs}_{2} \mathrm{CO}_{3}$ also displayed good efficiency (entry 10). We also investigated the above reaction at room temperature; the yield of the product was only $30 \%$ (entry 13). These obtained results suggested that the $\mathrm{Cu}^{+}-\mathrm{CP}, \mathrm{TEMPO}$, and a strong base medium are required to promote the oxidation reaction.
The reusability of $\mathrm{Cu}^{+}-\mathrm{CP} 2$ was investigated for the oxidations of benzyl alcohol and 4-methylbenzyl alcohol under the optimized conditions as described in Table S4 in the SI. It was observed that the $\mathrm{Cu}^{+}-\mathrm{CP}$ catalyst could be recycled and reused four times without any loss of activity. The XRD pattern of the recovered CP further confirmed its recyclability (Figure S7 in the $\mathrm{SI})$. As can be seen, there are only minor changes in the relative intensities of some peaks. This may be because TEMPO will coordinate with the active sites of $\mathrm{CP} .{ }^{8 a}$ Additionally, the catalyst could retain the integrity of its molecular structure, as evidenced by Fourier transform infrared (Figure S8 in the SI).

In order to extend the scope of the aerobic oxidation by $\mathrm{Cu}^{+}-$ $\mathrm{CP}$ assisted by TEMPO, we performed aerobic oxidation of various alcohols (Table 1). The electronic nature of the

Table 1. $\mathrm{Cu}^{+}-\mathrm{CP}$ 2/TEMPO Catalyzed the Aerobic Oxidation of Primary and Secondary Alcohols ${ }^{a}$

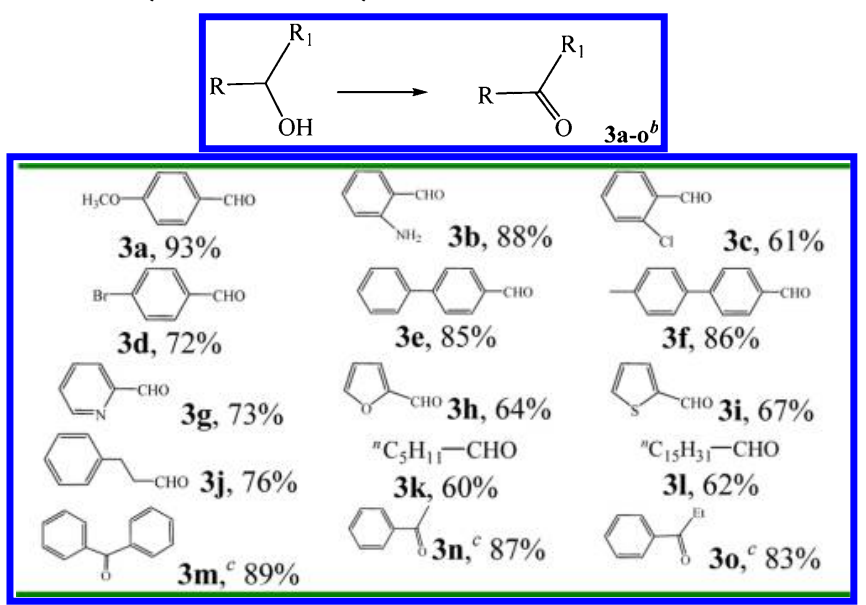

${ }^{a}$ Reaction conditions: alcohol $(1 \mathrm{mmol}), \mathrm{CsOH}(1 \mathrm{mmol}), \mathrm{Cu}^{+}-\mathrm{CP} 2$ (0.02 mmol), TEMPO (0.1 mmol), $\mathrm{CH}_{3} \mathrm{CN}(5 \mathrm{~mL})$, air atmosphere, $80{ }^{\circ} \mathrm{C}, 12$ h. ${ }^{b}$ Isolated yield. ${ }^{c}$ In the absence of TEMPO.

substituents on the benzylic alcohol did have an effect on the reaction. Electron-donating substrates reacted to give the products $\mathbf{3} \mathbf{a}$ and $\mathbf{3 b}$, and the yields (93 and $88 \%$ ) are obviously higher than the yields of electron-withdrawing substrates. The oxidation of heterocyclic alcohols proceeded smoothly to provide the desired products $3 \mathbf{g}-3 \mathbf{i}$ in moderate yield (64$73 \%)$. In the case of aliphatic alcohol, the product $3 \mathbf{j}-\mathbf{3 l}$ yields $(60-76 \%)$ were lower than those of the benzylic alcohols. It was noteworthy that the aerobic oxidation of secondary alcohols also gave the expected products $3 \mathbf{m}-\mathbf{3 o}$ in good yield (83-89\%) only using $\mathrm{Cu}^{+}-\mathrm{CP}$ in the absence of TEMPO, while the oxidation of 1-phenylethanol catalyzed by $\mathrm{Cu}_{3}$ (BTC) $)_{3} /$ TEMPO gave the product $3 \mathrm{n}$ with only a very low yield $(14 \%) .{ }^{8 a}$

Prompted by the good results obtained in the aerobic oxidation of alcohols catalyzed by $\mathrm{Cu}^{+}-\mathrm{CP}$, we explored whether this catalytic system would allow the preparation of 2arylbenzoxazoles from benzyl alcohols. The results obtained are summarized in Table 2. To our delight, under the same conditions, benzyl alcohol and 2-aminophenol were efficiently converted to the 2-phenylbenzoxazole 4a (82\%). Subsequently, the reactions of 2-aminophenol with benzylic alcohols bearing methyl and methoxy groups were investigated, and good yields were obtained ( 85 and $86 \%$ ). In contrast to 2 -monoarylbenzoxazoles, only the two examples of 2-biarylbenzoxazoles $4 \mathrm{~d}$ and $4 \mathrm{e}$ have been reported. ${ }^{13}$ To broaden the substrate scope, we further investigated 2 -aminophenol with a variety of electronic and 
Table 2. $\mathrm{Cu}^{+}$-CP 2/TEMPO-Catalyzed Aerobic Oxidative Synthesis of 2-Arylbenzoxazoles ${ }^{a}$

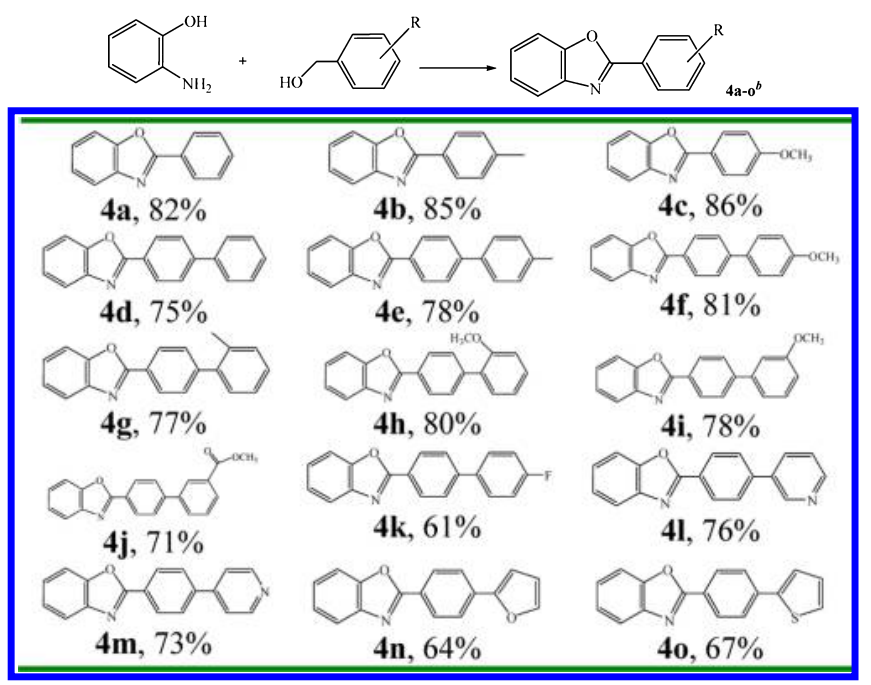

${ }^{a}$ Reaction conditions: 2-aminophenol $(1 \mathrm{mmol})$, alcohol $(1.2 \mathrm{mmol})$, $\mathrm{CsOH}(1 \mathrm{mmol}), \mathrm{Cu}^{+}-\mathrm{CP}(0.02 \mathrm{mmol})$, TEMPO $(0.1 \mathrm{mmol})$, $\mathrm{CH}_{3} \mathrm{CN}(5 \mathrm{~mL})$, air atmosphere, $80{ }^{\circ} \mathrm{C}, 12 \mathrm{~h} .{ }^{b}$ Isolated yield.

structural biarylmethanols. The corresponding 2-biarylbenzoxazoles $\mathbf{4 f}-\mathbf{4 k}$ were isolated in moderate-to-good yields (61$81 \%)$. Finally, this protocol was found also to proceed successfully with 4-heteroarylbenzyl alcohols, furnishing moderate yields (64-76\%). The detailed structure of $4 \mathrm{~h}$ was confirmed by single-crystal X-ray crystallography (Figure S2c in the SI).

In summary, we have synthesized two coordination polymers containing the dinuclear $\mathrm{Cu}^{\mathrm{II}}$ and tetranuclear $\mathrm{Cu}^{\mathrm{I}}$ units. The latter cuprocupric CP combined with TEMPO shows surprising catalytic performnace in the aerobic oxidation of primary and secondary alcohols under an air atmosphere. It is easy to synthesize and can be recycled and reused for four runs without any significant loss of catalytic activity. Moreover, this catalytic system has been successfully applied to the synthesis of 2arylbenzoxazoles from benzyl alcohols and 2-aminophenol.

\section{ASSOCIATED CONTENT}

\section{S Supporting Information}

$\mathrm{X}$-ray crystallographic details in CIF format, experimental details, spectral data, and additional figures and tables. This material is available free of charge via the Internet at http://pubs.acs.org.

\section{AUTHOR INFORMATION}

\section{Corresponding Authors}

*E-mail: xubohan@163.com.

*E-mail: wlya@lynu.edu.cn.

\section{Notes}

The authors declare no competing financial interest.

\section{ACKNOWLEDGMENTS}

We are grateful to the National Natural Science Foundation of China (Grants 21272110, 21273101, and 21171173), the Foundation of the Program for Backbone Teachers in Universities of Henan Province (Grants 2013GGJS151 and 2012GGJS158) and Tackle Key Problem of Science and Technology Project of Henan Province, China (Grant 142102310483), Science Foundation of Henan Education
Department (14A150049), and Innovation Scientists and Technicians Troop Construction Projects of Henan Province.

\section{REFERENCES}

(1) (a) Bäckvall, J. E. Modern Oxidation Methods; Wiley-VCH: Berlin, 2004. (b) Tojo, G.; Fernández, M. Oxidation of Alcohols to Aldehydes and Ketones; Basic Reactions in Organic Synthesis; Springer: New York, 2010. (c) Parmeggiani, C.; Cardona, F. Green Chem. 2012, 14, 547-564.

(2) (a) Stahl, S. S. Angew. Chem. Int. Ed. 2004, 43, 3400-3420. (b) Mallat, T.; Baiker, A. Chem. Rev. 2004, 104, 3037-3058. (c) Gligorich, K. M.; Sigman, M. S. Chem. Commun. 2009, 26, 38543856.

(3) (a) Punniyamurthy, T.; Rout, L. Coord. Chem. Rev. 2008, 252, 134-154. (b) Allen, S. E.; Walvoord, R. R.; Padilla-Salinas, R; Kozlowski, M. C. Chem. Rev. 2013, 113, 6234-6458.

(4) (a) Mase, N.; Mizumon, T.; Tatemoto, Y. Chem. Commun. 2011, 7, 2086-2088. (b) Hoover, J. M.; Stahl, S. S. I. Am. Chem. Soc. 2011, 133, 16901-16910. (c) Hoover, J. M.; Steves, J. E.; Stahl, S. S. Nat. Protoc. 2012, 7, 1161-1166. (d) Hoover, J. M.; Ryland, B. L.; Stahl, S. S. I.Am. Chem. Soc. 2013, 135, 2357-2367. (e) Steves, J. E.; Stahl, S. S. I.Am. Chem. Soc. 2013, 135, 15742-15745. (f) Cao, Q.; Dornan, L. M.; Rogan, L.; Hughes, N. L.; Muldoon, M. I. Chem. Commun. 2014, 35, 45244526. (g) Ryland, B. L.; Stahl, S. S. Anqew. Chem.. Int. Ed. 2014, 53, $8824-8836$.

(5) (a) Yang, G. Y.; Zhu, W. M.; Zhang, P. K.; Xue, H. Z.; Wang, W.; Tian, J. S.; Song, M. P. Adv. Sunth. Catal. 2008, 350, 542-546. (b) Herbert, M.; Montilla, F.; Galindo, A. Dalton Trans. 2010, 3, 900907.

(6) (a) Wang, Z.; Chen, G.; Ding, K. L. Chem. Rev. 2009, 109, 322359. (b) Yoon, M.; Srirambalaji, R.; Kim, K. Chem. Rev. 2012, 112, 1196-1231. (c) Liu, J. W.; Chen, L. F.; Cui, H.; Zhang, J. Y.; Zhang, L.; Su, C. Y. Chem. Soc. Rev. 2014, 43, 6011-6061.

(7) (a) Thomas, F.; Gellon, G.; Gautier-Luneau, I.; Saint-Aman, E.; Pierre, J. L. Angew. Chem. Int. Ed. 2002, 41, 3047-3050. (b) Figiel, P. J.; Leskelä, M.; Repo, T. Adv. Sunth. Catal. 2007, 349, 1173-1179. (c) Mahmudov, K. T.; Kopylovich, M. N.; Silva, M. F. C. G.; Figiel, P. J.; Karabach, Y. Y.; Pombeiro, A. J. L. J. Mol. Catal. A: Chem. 2010, 318, 4450. (d) Ma, Z.; Wei, L. J.; Alegria, E. C. B. A.; Martins, L. M. D. R. S.; Silva, M. F. C. G.; Pombeiro, A. J. L. Dalton Trans. 2014, 43, 4048-4050.

(8) (a) Dhakshinamoorthy, A.; Alvaro, M.; Garcia, H. ACS Catal. 2011, 1, 48-53. (b) Paul, M.; Adarsh, N. N.; Dastidar, P. Cryst. Growth Des. 2014, 14, 1331-1337. (c) Qi, Y.; Luan, Y.; Wu, J.; Peng, X.; Wang, G. Chem.-Eur. I. 2014, 21, 1589-1597.

(9) Li, L. C.; Matsuda, R.; Tanaka, I.; Sato, H.; Kanoo, P.; Jeon, H. J.; Foo, M. L.; Wakamiya, A.; Murata, Y.; Kitagawa, S. L. Am. Chem. Soc. 2014, 136, 7543-7546.

(10) (a) Xu, C.; Li, H. M.; Xiao, Z. Q.; Wang, Z. Q.; Tang, S. F.; Ji, B. M.; Hao, X. Q.; Song, M. P. Dalton Trans. 2014, 43, 10235-10247. (b) Xu, C.; Li, H. M.; Yuan, X. E.; Xiao, Z. Q.; Wang, Z. Q.; Fu, W. J.; Ji, B. M.; Hao, X. Q.; Song, M. P. Org. Biomol. Chem. 2014, 12, 3114-3122. (c) Feng, X.; Feng, Y. Q.; Liu, L.; Wang, L. Y.; Song, H. L.; Ng, S. W. Dalton Trans. 2013, 42, 7741-7754.

(11) (a) Zhan, S. Z.; Li, M.; Zhou, X. P.; Ni, J.; Huang, X. C.; Li, D. Inorg. Chem. 2011, 50, 8879-8892. (b) Chen, Y. Q.; Li, G. R.; Chang, Z.; Qu, Y. K.; Zhang, Y. H.; Bu, X. H. Chem. Sci. 2013, 4, 3678-3682. (c) Baruah, B.; Gabriel, G. J.; Akbashev, M. J.; Booher, M. E. Lanomuir 2013, 29, 4225-4234.

(12) (a) Cheng, J. K.; Chen, Y. B.; Wu, L.; Zhang, J.; Wen, Y. H.; Li, Z. J.; Yao, Y. G. Inorg. Chem. 2005, 44, 3386-3388. (b) Chen, Y.; Li, J. L.; Tong, G. S. M.; Lu, W.; Fu, W. F.; Lai, S. W.; Che, C. M. Chem. Sci. 2011, 2, 1509-1514.

(13) (a) Geigy, C. Patent DE2309614, 1973. (b) Teo, Y. C.; Riduan, S. N.; Zhang, Y. G. Green Chem. 2013, 15, 2365-2387. 